\title{
Heroínas Digitais: Um relato de experiência com meninas do ensino fundamental
}

\author{
Emely V. V. Albernaz Lopes $^{1}$, Valguima V. Viana Aguiar Odakura ${ }^{1}$ \\ ${ }^{1}$ Faculdade de Ciências Exatas e Tecnologias - FACET \\ Universidade Federal da Grande Dourados - UFGD \\ Caixa Postal 364 - 79.804-970 - Dourados - MS - Brasil \\ emely.albernaz@gmail.com, valguima.odakura@gmail.com
}

\begin{abstract}
This paper reports the experience of the workshops held in 2019 for girls in elementary school, whose objective was to address the representation of women in the area of science, especially technology, and concepts that allow the reflection of gender equity in society. Bearing in mind that, there is a need for many initiatives that de-characterize gender inequality, given that it is one of the UN objectives to be achieved by 2030, the Heroinas Digitais project promoted coordinated actions with teaching workshops on the use of Web 2.0 tools and programming in blocks, in order to encourage dialogues and reflections, exercising critical thinking.
\end{abstract}

Resumo. Neste trabalho é relatado a experiência das oficinas realizadas no ano de 2019 para meninas do ensino fundamental, cujo o objetivo foi abordar a representação de mulheres na área da ciência, principalmente da tecnologia, e conceitos que permitem a reflexão da equidade de gênero na sociedade. Haja vista que, há necessidade de muitas iniciativas que descaracterizem a desigualdade de gênero, dado que é um dos objetivos da ONU a ser cumprido até 2030, o projeto Heroínas Digitais promoveu ações coordenadas com oficinas de ensino à utilização de ferramentas Web 2.0 e programação em blocos, a fim de incentivar diálogos e reflexões, exercitando o pensamento crítico.

\section{Introdução}

A Cúpula de Desenvolvimento Sustentável com os Estados-Membros da Organização das Nações Unidas (ONU) lançaram uma agenda contendo 17 Objetivos de Desenvolvimento Sustentável a serem cumpridas até 2030 , no qual o $5^{\circ}$ objetivo compreendese a igualdade de gênero [das Nações Unidas (ONU) 2015]. A vista disso, em 2011 foi criado o programa Meninas Digitais da Sociedade Brasileira da Computação (SBC) [Maciel and Bim 2017], cujo objetivo é despertar o interesse para áreas tecnológicas em meninas do fundamental e médio, e incentivar a permanência em cursos superiores, bem como ampliar os debates e informações sobre gênero no Brasil.

Neste enquadramento de ações, é importante a disseminação da desconstrução de esteriótipos que configuram a desigualdade na sociedade em vários níveis educacionais, conforme ressaltado por [Prates 2014]. Um dos projetos que trabalha nesse âmbito é o de [Saccol et al. 2019], para meninas do ensino fundamental, sendo importante para ampliar o conhecimento da área da Computação, promovendo-a, mas também como ação de representatividade e de descaracterização de desigualdade de gênero. 
Desta maneira, este trabalho tem como objetivo descrever as ações de representatividade feminina na história da computação, empoderamento feminino e desconstrução de alguns esteriótipos através de oficinas para meninas do ensino fundamental. $\mathrm{O}$ artigo encontra-se dividido nas seguinte maneira: seção 2 a descrição do relato de experiência; seção 3 lições aprendidas; e por fim na seção 4 contendo as considerações finais.

\section{Relato de Experiência}

O projeto Heroínas Digitais, parceiro do programa Meninas de Digitais da SBC, iniciou as atividades de 2019, em março, em uma escola municipal. As oficinas tiveram duração total 8 meses, divididas em dois semestres, cujo o primeiro realizou-se oficinas para utilização de ferramentas Web 2.0 e o segundo semestre contemplou a programação em blocos. Estas atividades do projeto eram compostas por 04 ministrantes voluntárias, acadêmicas do curso de Engenharia de Computação da Universidade Federal da Grande Dourados. As oficinas atenderam 13 alunas, de 11 a 13 anos, do $6^{\circ}$ ao $7^{\circ}$ do ensino fundamental, nas dependências do laboratório de informática da escola, ás sextas-feiras a partir das 13:30 até as 15:00, sendo o tempo dividido em 05 partes como mostrado na tabela 1 abaixo:

Tabela 1. Tabela de Oficina Segmentada em Partes correlacionado ao Tempo
\begin{tabular}{|c|c|l|}
\hline Partes & $\begin{array}{c}\text { Duraçäo } \\
\text { (min.) }\end{array}$ & \multicolumn{1}{c|}{ Descrição } \\
\hline 01 & 05 & $\begin{array}{l}\text { Apresentação de uma mulher da história na tecnologia. É uma breve } \\
\text { descrição dos domínios pelos quais essas mulheres ficaram conhecidas e se } \\
\text { tornaram referência, de forma listada. }\end{array}$ \\
\hline $\mathbf{0 2}$ & 10 & $\begin{array}{l}\text { Explicação da ferramenta e seus objetivos. Envolve a esquematização de } \\
\text { acesso e uso da ferramenta e descrição da proposta de atividade para } \\
\text { fixação. }\end{array}$ \\
\hline $\mathbf{0 3}$ & 60 & $\begin{array}{l}\text { Atividade Prática. Nessa parte, as alunas realizam a atividade proposta } \\
\text { utilizando a ferramenta. Além disso, os voluntários da oficina ficam a } \\
\text { disposição para dúvidas e orientação técnicas. }\end{array}$ \\
\hline $\mathbf{0 4}$ & 13 & $\begin{array}{l}\text { "Momento meninas". Trata temas de empoderamento feminino, com caráter } \\
\text { informativo e reflexivo. Contendo: Explicaçães de conceitos, videos } \\
\text { motivacionais e imagens de artistas do instagram. }\end{array}$ \\
\hline $\mathbf{0 5}$ & 02 & $\begin{array}{l}\text { Gamificação. Incentiva a participação nas oficinas, a produção das } \\
\text { atividades e desincentivo as falta. }\end{array}$ \\
\hline
\end{tabular}

O tempo compreendido para as ações propostas transcorreram em 18 minutos, sendo 5 minutos para apresentação de mulheres que foram importantes para história da tecnologia ou ciência, conjuntamente com a listagem de seus feitos e 13 minutos para o denominado "Momento Meninas", no qual compreende-se na apresentação de conceitos, imagens, ilustrações e vídeos de cunho social que possibilitam a desconstrução de esteriótipos, diálogos reflexivos e senso crítico, detalhado nas subseções a seguir. Além disso, os últimos 2 minutos para gamificação que consistia na distribuição de pontos para os presentes na oficina, participações ativas, como manifestações verbais, e para as conclusões das atividades propostas, sendo idênticos em ambos semestres,.

\subsection{Oficinas Primeiro Semestre}

No primeiro semestre do ano de 2019, as ações para expandir a representatividade e a disseminação de conceitos visando o conhecimento para descaracterização de padrões sociais, foram inseridas nas oficinas das ferramentas Web 2.0, os quais são apresentados na Tabela 2. 
Estas oficinas apresentaram sete mulheres: Ada Lovelace, Grace Hopper, Hedy Lamarr, Mary k. Keller, Jean Sammet, Francis Allen e Carol Shaw. As intervenções nomeadas Apresentações transcorriam da seguinte maneira: primeiramente exibido apenas a imagem e lhes perguntado sobre a identidade da mesma, depois uma sequência listada com o nome, realizações e importância e por fim a opinião a respeito do exposto. Este último, foram manifestações simples, objetivas e uma anuência, de forma geral, positiva. O objetivo da atividade foi salientar a importância das mulheres na contribuição da tecnologia, historicamente até hoje, e enfatizar a representação feminina.

Tabela 2. Mapa de Atividades relativa as Ferramentas Web 2.0

\begin{tabular}{|c|c|c|}
\hline \multicolumn{3}{|c|}{$\begin{array}{l}\text { Tema: Ferramentas web } 2.0 \\
\text { Carga horária por aula: } 1 \mathrm{~h} \text { e } 30 \mathrm{~min} \\
\text { Oficinas: } 10\end{array}$} \\
\hline Oficina & Ferramenta & Descrição \\
\hline 1 & Webmail - Gmail & $\begin{array}{l}\text { Nºficinas: } 01 \\
\text { Apresentação: Ada Lovelace; Explicação da ferramenta e seus objetivos: Gmail; Atividade: } \\
\text { Criação da conta; "Momento meninas": Video 'Menina pode ser o que quiser'; Diferenciação } \\
\text { de equidade vs. igualdade; e Introduçãao do tema empoderamento feminino. }\end{array}$ \\
\hline 2 & $\begin{array}{l}\text { Storyboard - } \\
\text { Storybird }\end{array}$ & $\begin{array}{l}\text { Nºficinas: } 03 \\
\text { Apresentação: Grace Hopper, Hedy Lamarr ; Explicação da ferramenta e seus objetivos: } \\
\text { Storybird; Atividade: Criação de uma história sobre uma mulher inspiradora do convivio; } \\
\text { "Momento meninas": Video 'Desafio da igualdade'; Imagens de representações femininas } \\
\text { diferentes pela artista Helena Morani; e Conceito de empoderamento feminino. }\end{array}$ \\
\hline 3 & $\begin{array}{l}\text { Mapa Mental - } \\
\text { GoConqr }\end{array}$ & $\begin{array}{l}\text { Nºficinas: } 02 \\
\text { Apresentação: Mary K. Keller e Jean Sammet e breve apresentação dos graus de } \\
\text { escolaridade; Explicação da ferramenta e seus objetivos: Mapa mental; Atividade: O que } \\
\text { meninas gostam; “Momento meninas": Revisão do conceito de empoderamento feminino e } \\
\text { conceito de sororidade; Diferenciação do feminismo, femismo, machismo e sexismo; Conceito } \\
\text { de feminismo; Apresentação da tirinha editada da ilustradora Helô D'Angelo 'Não preciso de } \\
\text { feminismo'; Video 'Discurso de Greta Thunberg'. }\end{array}$ \\
\hline 4 & Quadrinhos - Pixton & $\begin{array}{l}\text { Nºficinas: } 02 \\
\text { Apresentação: Francis Allen; Explicação da ferramenta e seus objetivos: Quadrinhos; } \\
\text { Atividade: O que quero ser quando crescer?; “Momento meninas": Revisão dos conceitos } \\
\text { anteriores; Sequência das mulheres da tecnologia apresentadas anteriormente; Video 'O que } \\
\text { significa para você fazer algo tipo menina?'. }\end{array}$ \\
\hline 5 & Quiz - GoConqr & $\begin{array}{l}\text { Nºficinas: } 02 \\
\text { Apresentação: Carol Shaw; Explicação da ferramenta e seus objetivos: Quiz; Atividade: } \\
\text { Mulheres e conceitos aprendidos na oficina; "'Momento meninas": Revisão dos conceitos } \\
\text { anteriores; Sequência das mulheres da tecnologia apresentadas anteriormente; Video 'Tente. } \\
\text { Fracasse. Aprenda'. }\end{array}$ \\
\hline
\end{tabular}

A parte Momento meninas foi composta por vídeos, conceitos curtos, ilustrações, imagens e tirinhas. Os vídeos selecionados tiveram o objetivo de despertar para assuntos que são tabus e as reproduções involuntários de comportamentos machistas observadas na sociedade. Além disso, vídeos de discursos de jovens ativistas femininas enfatizando a importância de meninas em eventos relevantes para a mudança social. Os links dos vídeos utilizados na oficina estão disponíveis para consulta ${ }^{1}$.

Conjuntamente, os conceitos foram explicados de maneira simples, utilizando exemplos, para facilitar o entendimento. As ilustrações e tirinhas de artistas femininas, alcançaram percepções relevantes sobre diferentes corpos, estilos, interesses e importância histórica do feminismo para conquistas das mulheres.

Foram propostas Atividades que correlacionassem com os temas de representatividade e equidade de gênero, abordando os seguintes assuntos: 'Crie uma história com uma mulher inspiradora que você conhece' com a ferramenta Storybird, 'O que meninas gostam?' com a técnica mapa mental no GoConqr, 'O que quero ser quando crescer?' criado com a ferramenta de quadrinhos Pixton e 'Mulheres e conceitos aprendidos' desenvolvido em formato de quiz também no GoConqr.

\footnotetext{
${ }^{1}$ Links dos vídeos utilizados na oficina, disponível em: encurtador.com.br/qxDST
} 


\subsection{Oficinas Segundo Semestre}

Da mesma maneira, o segundo semestre prosseguiram com a proposta da primeira parte do ano, contudo desta vez, intercalada com as oficinas de programação em bloco com code.org, seguindo a sequência de atividades representadas na tabela 3 .

Tabela 3. Mapa de Atividades relativa as Oficinas de Programação em Bloco

\begin{tabular}{|c|c|c|}
\hline \multicolumn{3}{|c|}{$\begin{array}{l}\text { Tema: Ferramenta de programação em Bloco - Code. org } \\
\text { Carga horária por aula: } 1 \mathrm{~h} \text { e } 30 \mathrm{~min} \\
\text { Oficinas: } 07\end{array}$} \\
\hline Oficina & Titulo & Descrição \\
\hline 1 & Raciocínio lógico & $\begin{array}{l}\text { Apresentação: Sequência das mulheres da tecnologia apresentadas anteriormente; } \\
\text { Explicação da ferramenta e seus objetivos: Gmail (Revisão da ferramenta para quem não se } \\
\text { lembrava ou não tinha) e conceitualização de raciocínio lógico; Atividade: Desafios de } \\
\text { raciocínio; "Momento meninas": Revisão dos conceitos anteriores. }\end{array}$ \\
\hline 2 & $\begin{array}{l}\text { Algoritmos e } \\
\text { Programação }\end{array}$ & $\begin{array}{l}\text { Apresentação: Camila Achutti; Explicação da ferramenta e seus objetivos: } \\
\text { Conceitos iniciais de algoritmos e programação; Atividade: Programação no papel; "Momento } \\
\text { meninas": Video 'Mulheres Fantásticas - Malala Yousafzai'; e Reflexão sobre 'O que é ser } \\
\text { mulher?'. }\end{array}$ \\
\hline 3 & Prática 01 & $\begin{array}{l}\text { Apresentação: katie Bouman; Explicação da ferramenta e seus objetivos: Explicação da } \\
\text { interface, comandos da ferramenta e sequência de blocos; Atividade: Curso } 02 \text { - fase } 01,02 \text { e } \\
03 \text {; "Momento meninas": Dinâmica 'Brinquedo de menina ou brinquedo de menino?'; e Video } \\
\text { 'Qual boneco é bom ou mau?'. }\end{array}$ \\
\hline 4 & Prática 02 & $\begin{array}{l}\text { Apresentação: Katherine Johnson; Explicação da ferramenta e seus objetivos: Sequência } \\
\text { de blocos - parte II e ângulos; Atividade: Curso } 02 \text { - fase 04; "Momento meninas": Video } \\
\text { 'Animanimals: Ant'; e Video 'O Casaco'. }\end{array}$ \\
\hline 5 & Prática 03 & $\begin{array}{l}\text { Apresentação: Dorothy Vaughan; Explicação da ferramenta e seus objetivos: Conceitos e } \\
\text { estruturas de repetição; Atividade: Curso } 02 \text { - fase } 05 \text { e 06; “Momento meninas": Vídeo 'Você } \\
\text { está perdido no mundo, assim como eu'; e Video 'Alike'. }\end{array}$ \\
\hline 6 & Prática 04 & $\begin{array}{l}\text { Apresentação: Mary Jackson; Explicação da ferramenta e seus objetivos: Revisão de } \\
\text { repetição; Atividade: Curso } 02 \text { - fase 08; "Momento meninas": Apresentação do Instagram do } \\
\text { grupo Heroínas Digitais. }\end{array}$ \\
\hline 7 & Prática 05 & $\begin{array}{l}\text { Apresentação: Sequência das mulheres da tecnologia apresentadas anteriormente; } \\
\text { Explicação da ferramenta e seus objetivos: Depuração; Atividade: Curso } 02 \text { - fase } 09 \text { e 10; } \\
\text { "Momento meninas": Conceito de representatividade; e Video 'O Poder da } \\
\text { Representatividade'; e Cartilha 'Representatividade feminina na ciência e tecnologia' por } \\
\text { dicasdemulher.com.br }\end{array}$ \\
\hline
\end{tabular}

A ação Apresentação mostraram 05 mulheres da tecnologia e ciência: Camila Achutti, katie Bouman, Katherine Johnson, Dorothy Vaughan e Mary Jackson. A escolha destas mulheres foi pela necessidade de incluir outros perfis de representações, desse modo refletindo a escolha da cientista da computação e empreendedora Camila Achutti como representação feminina da computação no âmbito nacional, a Katie Bouman reconhecida pela criação do algoritmo que permitiu a reprodução da primeira imagem de um buraco negro e Katherine Johnson, Dorothy Vaughan e Mary Jackson as famosas cientistas retratadas no filme 'Hidden Figures' (título brasileiro: Estrelas além do tempo) representando as mulheres negras cientistas da NASA.

O Momento Meninas compreenderam assuntos sobre: 'O que é ser mulher?', onde foi mostrado uma sequência de relatos de profissionais da área de jornalistica, abrindo reflexões e manifestações sobre o tema; A dinâmica 'Brinquedo de menina ou brinquedo de menino', no qual foi apresentado figuras de brinquedos para a turma se manifestar para qual gênero se destinava, além de vídeos sobre racismo, diferentes perspectivas sobre uma ação, consumo abusivo de redes sociais, reflexões sobre o sistema de educação e trabalho na sociedade, atitudes de empatia e compaixão e representatividade feminina.

\section{Lições Aprendidas}

De maneira geral, as Atividades práticas propostas no primeiro semestre tiveram bons resultados, porém o tema 'O que meninas gostam?' foi muito abrangente, e não atingiu o objetivo tencionado pelo projeto. Também, notou-se, no Momento meninas, 
que os vídeos eram mais impactantes e geravam mais manifestações orais do que as apresentações, mesmo que curtas, dos conceitos. O uso de imagens foi uma alternativa para exemplificação em conjunto da descrição dos conceitos abordados.

Além disso, observou-se a necessidade de realizar algumas estratégias de acordo com as necessidades apresentadas pelas alunas, pois visto que as Apresentações aconteciam uma vez por semana e nos 5 minutos iniciais, quando perguntadas sobre a mulher da semana anterior, havia uma dificuldade de relembrar. Por isso, decidiu-se realizar revisões das mulheres passadas anteriormente, antes de suceder novas apresentações, a cada oficina, além de fazer associações com pequenas frases, exemplo: Ada Lovelace, criou o primeiro algoritmo.

Além do que se compreende os objetivos do projeto, foi desenvolvido um material sobre títulos acadêmicos, quando percebido o desconhecimento destes pelas alunas, a criação de uma rede social do projeto para que as meninas tivessem acesso a conteúdos adequados no âmbito do programa, e, no encerramento, uma visita até a Universidade apresentando-a como um lugar acessível e possível, caso queiram ingressar futuramente.

\section{Considerações Finais}

Este trabalho descreve as atividades no contexto de ações que aumentam a representatividade da mulher na história da tecnologia e conceitos que reflexionam a igualdade de gênero para meninas em uma escola municipal. O projeto visa contribuir com a empoderamento de meninas através de oficinas de tecnologias e pensamento computacional, associadas igualdade de gênero.

As oficinas realizaram Apresentações que consistiram em apresentações de mulheres importantes para história na tecnologia e da ciência, o denominado "Momento Meninas" que foram explicações de conceitos importantes para entender o empoderamento feminino, e algumas atividades práticas que permitiram a inserção do tema.

Para trabalhos futuros, o projeto visa elaborar atividades interventivas abordando diferentes assuntos dentro do contexto de equidade e que permita o desenvolvimento de habilidades exigidas no mercado de trabalho.

\section{Referências}

das Nações Unidas (ONU), O. (2015). Objetivo 5. alcançar a igualdade de gênero e empoderar todas as mulheres e meninas. Disponível em:https://nacoesunidas.org/pos2015/ods5/ acessado em 14/05/2020.

Maciel, C. and Bim, S. A. (2017). Programa meninas digitais-ações para divulgar a computação para meninas do ensino médio. Anais do Computer on the Beach, pages 327-336.

Prates, M. I. R. N. (2014). Educação para a igualdade de género: um estudo de caso numa instituição de educação de infância. PhD thesis, Instituto Politécnico de Portalegre.

Saccol, A., Castanho, C., Silva, E., Spies, E., and Alves, V. (2019). Gurias digitais: Inclusão de meninas na área de ti. In Anais do XIII Women in Information Technology, pages 194-198. SBC. 